\title{
The Impact of Pollution on Worker Productivity ${ }^{\dagger}$
}

\author{
Joshua Graff Zivin and \\ University of California-San Diego, School of International Relations and Pacific Studies and \\ Department of Economics, 9500 Gilman Dr. 0519, La Jolla, CA 92093, and NBER
}

\author{
Matthew Neidell \\ Columbia University, Department of Health Policy and Management, Mailman School of Public \\ Health, 600 W. 168th Street, 6th Floor, New York, NY 10032, and NBER \\ Joshua Graff Zivin: jgraffzivin@ucsd.edu; Matthew Neidell: mn2191@columbia.edu
}

\begin{abstract}
As one of the primary factors of production, labor is an essential element in every nation's economy. Investing in human capital is widely viewed as a key to sustaining increases in labor productivity and economic growth. While health is increasingly seen as an important part of human capital, environmental protection, which typically promotes health, has not been viewed through this lens. Indeed, such interventions are typically cast as a tax on producers and consumers, and thus a drag on the labor market and the economy in general. Given the large body of evidence that causally links pollution with poor health outcomes (e.g., Bell et al. 2004; Chay and Greenstone 2003; Currie and Neidell 2005; Dockery et al. 1993; Pope et al. 2002), it seems plausible that efforts to reduce pollution could in fact also be viewed as an investment in human capital, and thus a tool for promoting, rather than retarding, economic growth.
\end{abstract}

The key to this assertion lies in the impacts of pollution on labor market outcomes. While a handful of studies have documented impacts of pollution on labor supply (Carson, Koundouri, and Nauges 2011; Graff Zivin and Neidell forthcoming; Hanna and Oliva 2011; Hausman, Ostro, and Wise 1984; Ostro 1983), ${ }^{1}$ their focus on the extensive margin, where behavioral responses are nonmarginal, only captures high-visibility labor market impacts. Pollution is also likely to have productivity impacts on the intensive margin, even in cases where labor supply remains unaffected. Since worker productivity is more difficult to monitor than labor supply, these more subtle impacts may be pervasive throughout the workplace, so that even small individual effects may translate into large welfare losses when aggregated across the economy. There is, however, no systematic evidence to date on the direct impact of pollution on worker productivity. ${ }^{2}$ This paper is the first to rigorously assess this environmental productivity effect.

\footnotetext{
${ }^{\dagger}$ To view additional materials, visit the article page at http://dx.doi.org/10.1257/aer.102.7.3652. Correspondence to: Joshua Graff Zivin, jgraffzivin@ucsd.edu.

${ }^{1}$ Numerous cost-of-illness studies that focus on hospital outcomes such as length of hospital stay also implicitly focus on labor supply impacts.

${ }^{2}$ In a notable case study, Crocker and Horst (1981) examined the impacts of environmental conditions on 17 citrus harvesters. They found a small negative impact on productivity from rather substantial levels of pollution in Southern California in the early 1970s.
} 
Estimation of this relationship is complicated for two reasons. One, although datasets frequently measure output per worker, these measures do not isolate worker productivity from other inputs (i.e., capital and technology), so that obtaining clean measures of worker productivity is a perennial challenge. Two, exposure to pollution levels is typically endogenous. Since pollution is capitalized into housing prices (Chay and Greenstone 2005), individuals may sort into areas with better air quality depending, in part, on their income, which is a function of their productivity (Banzhaf and Walsh 2008). Furthermore, even if ambient pollution is exogenous, individuals may respond to ambient levels by reducing time spent outside, so that their exposure to pollution is endogenous (Neidell 2009).

In this paper, we use a unique panel dataset on the productivity of agricultural workers to overcome these challenges in analyzing the impact of ozone pollution on productivity. Our data on daily worker productivity is derived from an electronic payroll system used by a large farm in the Central Valley of California that pays its employees through piece rate contracts. A growing body of evidence suggests that piece rates reduce shirking and increase productivity over hourly wages and relative incentive schemes, particularly in agricultural settings (Bandiera, Barankay, and Rasul 2005, 2010; Lazear 2000; Paarsch and Shearar 1999, 2000; Shi 2010). Given the incentives under these contracts, our measures of productivity can be viewed as a reasonable proxy for productive capacity under typical work conditions.

We conduct our analysis at a daily level to exploit the plausibly exogenous daily fluctuations in ambient ozone concentrations. Although aggregate variation in environmental conditions is largely driven by economic activity, daily variation in ozone is likely to be exogenous. Ozone is not directly emitted but forms from complex interactions between nitrogen oxides $\left(\mathrm{NO}_{\mathrm{x}}\right)$ and volatile organic chemicals (VOCs), both of which are directly emitted, in the presence of heat and sunlight. Thus, ozone levels vary in part because of variations in temperature, but also because of the highly nonlinear relationship with $\mathrm{NO}_{\mathrm{x}}$ and VOCs. For example, the ratio of $\mathrm{NO}_{\mathrm{x}}$ to VOCs is almost as important as the level of each in affecting ozone levels (Auffhammer and Kellogg 2011), so that small decreases in $\mathrm{NO}_{\mathrm{x}}$ can even lead to increases in ozone concentrations, which has become the leading explanation behind the "ozone weekend effect" (Blanchard and Tanenbaum 2003). Moreover, regional transport of $\mathrm{NO}_{\mathrm{x}}$ from distant urban locations, such as Los Angeles and San Francisco, has a tremendous impact on ozone levels in the Central Valley (Sillman 1999). Given the limited local sources of ozone precursors, this suggests that the ozone formation process coupled with emissions from distant urban activities are the driving forces behind the daily variation in environmental conditions observed near this farm.

Furthermore, the labor supply of agricultural workers is highly inelastic in the short run. Workers arrive at the field in crews and return as crews, thus spending the majority of their day outside regardless of environmental conditions. Moreover, since we have measures of both the decision to work and the number of hours worked, we can test whether workers respond to ozone, and in fact we are able to rule out even small changes in avoidance behavior. Thus, focusing on agricultural workers greatly limits the scope for avoidance behavior, further ensuring that exposure to pollution is exogenous in this setting, and that we are detecting productivity impacts on the intensive margin. 
Although these workers are paid through piece-rate contracts, worker compensation is subject to minimum wage rules, which can alter the incentive for workers to supply costly effort. Since the minimum wage decouples daily job performance from compensation, workers may have an incentive to shirk. If pollution leads to more workers earning the minimum wage, and this in turn induces shirking, linear regression estimates will be upward biased. On the other hand, the threat of termination may provide a sufficient incentive to provide effort, particularly in our setting where output is easily verified and labor contracts are extremely short-lived, in which case linear regression models should be unbiased.

After merging this worker data with environmental conditions based on readings from air quality and meteorology stations in the California air monitoring network, we first estimate linear models that relate mean ozone concentrations during the typical workday to productivity. We find that ozone levels well below federal air quality standards have a significant impact on productivity: a 10 parts per billion (ppb) decrease in ozone concentrations increases worker productivity by 5.5 percent. To account for potential concerns about shirking, we artificially induce "bottom- coding" on productivity measures for observations where the minimum wage binds, and estimate censored regression models. Under this specification, the actual measures of productivity when the minimum wage binds no longer influence estimates of the impact of ozone on productivity. Thus, if the marginal effects of productivity on this latent variable differ from the marginal effects from our baseline linear model, this would indicate shirking is occurring. Our results, however, remain unchanged, suggesting that the threat of termination provides sufficient incentives for workers to supply effort even when compensation is not directly tied to output.

These impacts are particularly noteworthy as the US Environmental Protection Agency is currently contemplating a reduction in the federal ground-level ozone standard of approximately $10 \mathrm{ppb}$ (Environmental Protection Agency 2010). The environmental productivity effect estimated in this paper offers a novel measure of morbidity impacts that are both more subtle and more pervasive than the standard health impact measures based on hospitalizations and physician visits. Moreover, they have the advantage of already being monetized for use in the regulatory cost-benefit calculations required by Executive Order 12866 (The White House, 1994). In developing countries, where environmental regulations are typically less stringent and agriculture plays a more prominent role in the economy, this environmental productivity effect may have particularly detrimental impacts on national prosperity.

The paper is organized as follows. Section I briefly summarizes the relationship between ozone and health, and highlights potentially important confounders. Section II describes the piece-rate and environmental data. Section III provides a conceptual framework that largely serves to guide our econometric model, which is described in Section IV. Section V describes the results, with a conclusion provided in Section VI.

\section{Background on Ozone and Health}

Ozone affects respiratory morbidity by irritating lung airways, decreasing lung function, and increasing respiratory symptoms (Environmental Protection Agency 2006). Studies have 
consistently linked higher ozone concentrations with increased health care visits for respiratory diseases (see, e.g., Neidell 2009), but ozone can also lead to minor insults that may not necessitate the use of formal health care. For example, research finds decreases in forced-expiratory volume in mail carriers in Taiwan (Chan and Wu 2005) and agricultural workers in British Columbia, Canada (Brauer, Blair, and Vedal 1996) even at levels below prevailing air quality standards. Symptoms from ozone exposure can arise in as little as one hour, with effects exacerbated by exercise and with continued duration of exposure (see, e.g., Gong et al. 1986; Kulle et al. 1985; McDonnell et al. 1983), both of which are particularly relevant for our study population given the physical demands of the task and prolonged exposure. How these respiratory changes affect productivity is not well understood, though it is plausible to think that diminished lung functioning would negatively impact productivity for physically demanding work such as that found in agriculture.

Recovery from ozone, once removed from exposure, is also quite rapid. Nearly all lung functioning returns to baseline levels in healthy adults within 24 hours of exposure, although recovery can take longer for hyper-responsive adults with underlying health conditions (Folinsbee and Hazucha 2000; Folinsbee and Horvath 1986). ${ }^{3}$ Since ozone levels fall considerably overnight as heat and sunlight decline, we expect lagged ozone to have minimal impacts on the productivity of our healthy worker population. As a result, we focus our analyses primarily on the contemporaneous relationship between ozone and productivity. The impact of lagged ozone concentrations is also explored in order to confirm that our workers are indeed healthy.

As noted in the introduction, ozone formation depends, in part, on ambient temperatures. Human exposure to high temperature can lead to severe negative health effects, including heat cramps, exhaustion, and stroke, as well as more subtle impacts on endurance, fatigue, and cognitive performance (e.g., González-Alonso et al. 1999; Hancock, Ross, and Szalma 2007), all of which may diminish the productivity of workers. The impacts can arise in less than an hour (Hancock, Ross, and Szalma 2007) and are likely nonlinear, as it is mostly temperature extremes outside the "comfort zone" that appreciably affect health (Hancock and Warm 1989). As such, our empirical models will include flexible controls for temperature.

\section{Data}

Our data comes from a unique arrangement with an international software provider, Orange Enterprises (OE). OE customizes paperless payroll collection for clients, called the Payroll Employee Tracking (PET) Tiger software system. It tracks the progress of employees by collecting real-time data on attendance and harvest levels of individual farm workers in order to facilitate employee and payroll management. The PET Tiger software operates as follows. The software is installed on handheld computers used by field supervisors. At the beginning of the day, supervisors enter the date, starting time, and the crop being harvested. Each employee clocks in by scanning the unique barcode on his or her badge. Each time the employee brings a bushel, bucket, lug, or bin, his or her badge is swiped, recording the unit

\footnotetext{
${ }^{3}$ Although lung functioning recovers after exposure, long-term damage to lung cells may still occur (Tepper et al. 1989).
} 
and time. Data collected in the field is transmitted to a host computer by synchronizing the handheld with the host computer, which facilitates the calculation of worker wages.

We have purchased the rights to daily productivity data from a farm in the Central Valley of California that uses this system. To protect the identity of the farm, we can only reveal limited information about their operations. The farm, with a total size of roughly 500 acres, produces blueberries and two types of grapes during the warmer months of the year. The farm offers two distinct piece-rate contracts depending on the crop being harvested: time plus pieces (TPP) for the grapes and time plus all pieces (TPAP) for blueberries. Total daily wages $(w)$ from each contract can be described by the following equations:

$$
\begin{gathered}
\text { TPP: } w=8 h+p \cdot(q-\operatorname{minpcs} \cdot h) \cdot I(q>\operatorname{minpcs} \cdot h) \\
\text { TPAP }: w=8 h+p \cdot q \cdot I(q>\operatorname{minpcs} \cdot h)
\end{gathered}
$$

where the minimum wage is $\$ 8$ per hour, $h$ is hours worked, $p$ is the piece rate, $q$ is daily output, minpcs is the minimum number of hourly pieces to reach the piece rate regime, and $I$ is an indicator function equal to 1 if the worker exceeds the minimum daily harvest threshold to qualify for piece-rate wages and 0 otherwise. In both settings, if the worker's average hourly output does not exceed minpcs, the worker earns minimum wage. The marginal incentive for a worker whose output places them in the minimum wage portion of the compensation schedule is job security. In TPP, the marginal incentive in the piece rate regime is the piece rate. TPAP slightly differs from TPP in that it pays piece rate for all pieces when a worker exceeds the minimum hourly rate (as opposed to paying piece rate only for the pieces above the minimum). Hence, the payoff at minpcs is nonlinear and provides a stronger incentive to reach the threshold under this contract. The incentive beyond this kink remains linear as under TPP.

The worker dataset we obtained consists of a longitudinal file that follows workers over time by assigning workers a unique identifier based on the barcode of their employee badge. It includes information on the total number of pieces harvested by each worker, ${ }^{4}$ the location of the field, the type of crop, the terms of the piece rate contract, ${ }^{5}$ time in and out, and the gender of the worker. ${ }^{6}$ Data quality is extremely high, as its primary purpose is to determine worker wages. The analyses in this paper are based on data from the farm for their 2009 and 2010 growing seasons.

\footnotetext{
${ }^{4}$ For one of the three crops, harvests are done in crews of three and individual productivity is measured as the total output of the crew divided by the crew size. While crew work could introduce free-riding incentives, our measure of the environmental productivity effect will only be biased if these incentives change due to pollution. This will only occur if both of the following are true: workers are differentially affected by ozone and the complementarities in team production are very high (e.g., Leontief production). While each member of a crew has a specific task, they typically help each other throughout the day, suggesting that labor is indeed substitutable within the crew. Moreover, Hazucha et al. (2003) find little evidence of heterogeneous health impacts of ozone across healthy men and women. Thus, assigning average productivity measures to individuals within a crew should not bias our estimates.

${ }^{5}$ Piece-rate contracts, and thus minimum daily harvest thresholds, are fixed to the crop for the duration of the season. For simplicity, we label the two types of grapes as two crops given that they have different contracts.

${ }^{6}$ Although we have limited data on the demographic characteristics of our workers, demographics of piece-rate agricultural workers in California obtained from the National Agricultural Workers Survey, an employment-based random survey of agricultural workers, indicates these workers are poor, uneducated, and speak limited English, with the vast majority migrants from Mexico.
} 
Our measures of environmental conditions come from data on air quality and weather from the system of monitoring networks maintained by the California Air Resources Board (2012). These data offer hourly measures of various pollutants and meteorological elements at numerous monitoring sites throughout the state. The farm is in close proximity to several monitors: three monitors that provide measurements of ozone and other environmental variables are within 20 miles of the farm, with the closest less than 10 miles away. ${ }^{7}$ For all environmental variables, we compute an average hourly measure for the typical work day, which starts at 6 ам and ends at 3 рм.

We assign environmental conditions to the farm using data from the closest monitoring station to the farm. While studies find that ozone measurements at fixed monitors are often higher than measurement from personal monitors attached to individuals in urban settings (O'Neill et al. 2003), this is less of a concern in the agricultural setting where ratios of personal to fixed monitors have been found to be as high as 0.96 (Brauer and Brook 1995). Furthermore, even when the difference exists, the within-person variation is highly correlated with the within-monitor variation (O'Neill et al. 2003). As a crude test for spatial uniformity of ozone levels, we regress ozone levels from the closest monitor to the farm against the second closest monitor with data available for both years, which is roughly 30 miles away, and obtain an $R^{2}$ of $0.85 .^{8}$ Thus, despite its simplicity, we expect measurement error using our proposed technique for assigning ozone to the farm to be quite small.

Our data follows roughly 1,600 workers intermittently over 155 days. Table 1 shows summary statistics for worker output and characteristics, environmental variables, and a breakdown of the sample size. There are three main crops harvested by this farm. ${ }^{9}$ Under the TPAP contracts, which are used to harvest crop type 1, workers reach the piece-rate regime 24 percent of workdays. For the crops paid under TPP, workers reach the piece-rate regime 57 percent of workdays for crop 2 and 47 percent of workdays for crop 3. Under these contracts, the average hourly wages are $\$ 8.41, \$ 8.16$, and $\$ 8.41$ for each of the three crops, respectively. We also see that variation in worker output is equally driven by variation within as well as across workers. Worker tenure with the farm is rather short, averaging 20 days, and both genders are well represented. ${ }^{10}$

In terms of environmental variables, the average ambient ozone level for the day is under 50 $\mathrm{ppb}$, with a standard deviation of $13 \mathrm{ppb}$ and a maximum of $86 \mathrm{ppb}$. Since this measure of ozone is taken over the average workday from 6 AM to 3 PM, it corresponds closely with national ambient air quality standards (NAAQS), which are based on eight-hour ozone measures. Current NAAQS are set at $75 \mathrm{ppb}$, suggesting that, while ozone levels during work hours can lead to exceedances of air-quality standards, most workdays are not in violation of regulatory standards. ${ }^{11}$ Consistent with the area being prone to ozone formation,

\footnotetext{
${ }^{7}$ To protect the identity of the farm, we cannot reveal the exact distance.

${ }^{8}$ Comparable $R^{2}$ for temperature is 0.94 and for particulate matter less than $2.5 \mu g / \mathrm{m}^{3}$, another pollutant of much interest, is only 0.27 ; hence we do not focus on this important pollutant but include it as a covariate.

${ }^{9}$ The timing of the harvest is determined by when each crop is ready to be picked, so workers have little discretion over which crop to harvest on any given day. We explore the potential impact of worker selection into crops in Section VC.

$1^{10}$ Gender is not reported for 19 percent of the sample.

11 Violation of NAAQS is based on the daily maximum eight-hour ozone. Since our measure of ozone begins at 6 AM, a time when ozone levels are quite low, the daily maximum eight-hour ozone is generally higher than our measure.
} 
mean temperature and sunlight (as proxied by solar radiation) are high, and precipitation is low.

For a deeper look at productivity, Figure 1 plots the distribution of average pieces collected per hour by crop and overall, with a line drawn at the rate that corresponds with the level of productivity that separates the minimum wage from the piece-rate regime (the regime threshold). To combine productivity across crops, we standardize average hourly productivity by subtracting the minimum number of pieces per hour required to reach the piece-rate regime and dividing by the standard deviation of productivity for each crop, so the value that separates regimes is 0 . For the crop paid TPAP, we see evidence of mass displaced just before the regime threshold, which is consistent with the strong incentives associated with just crossing the threshold under this payment scheme. For the two crops paid TPP, the distribution of productivity follows a symmetric normal distribution quite closely, with the exception of some displacement immediately surrounding the regime threshold for crop 2 . Since crop 2 is harvested at a rate roughly 50 percent higher than crop 3 , as shown in Table 1, it may be easier for workers who are close to the threshold to push themselves just above it by collecting a little more. If shirking occurs when the minimum wage binds, then we would expect part of the distribution to be shifted away from the area just left of the regime threshold and into the left tail. These plots, however, do not exhibit such patterns, suggesting that shirking among those receiving a fixed wage is minimal.

The significant variation in pieces collected in Figure 1 is also noteworthy, as this is critical for obtaining precise estimates of the impact of ozone. Figures 2 and 3 further illustrate this variation both within and across workers. For Figure 2, we collapse the data to the worker level by computing each worker's mean daily productivity over time. For Figure 3, we collapse the data to the daily level by computing the mean output of all workers on each day. This significant variation suggests that both worker ability and environmental conditions appear to be important drivers of worker productivity.

To illustrate the relationship between ozone and temperature, Figure 4 plots the demeaned average hourly ozone and temperature by day separately for the 2009 and 2010 ozone seasons, with an indicator for days on which harvesting occurs for each crop. This Figure reveals considerable variation in both variables over time. Importantly, while ozone and temperature are often correlated-temperature is an input into the production of ozonethere is ample independent variation for conducting our proposed empirical tests. ${ }^{12} \mathrm{We}$ also control for temperature flexibly to ensure that we are properly accounting for this relationship.

\section{Conceptual Framework}

In this section, we develop a simple conceptual model to illustrate worker incentives under a piece-rate regime with a minimum wage guarantee. We begin by assuming that the output $q$ for any given worker is a function of effort $e$ and pollution levels $\Omega$. Workers are paid piece rate $p$ per unit output, but only if their total daily wage is at least as large as the daily

\footnotetext{
${ }^{12}$ The $R^{2}$ from a regression of ozone on temperature alone is 0.61 . When we more flexibly control for temperature and also include additional environmental variables as specified in the econometric model (described below), the $R^{2}$ increases to 0.85 .
} 
minimum wage $\bar{y} \cdot{ }^{13}$ In anticipation of our empirical model, we let zero denote the threshold level of output at which workers graduate from the minimum wage regime. Since employment contracts are extremely shortlived, we assume that the probability of job retention $\tau$ is an increasing function of output levels $q$ when $q<0 .{ }^{14}$ Denoting the costs of worker effort as $c(e)$ and the value associated with job retention as $k$, we can characterize the workers' maximization problem above and below the threshold output level.

For those workers whose output level qualifies them for the piece-rate wage $(q \geq 0)$, effort will be chosen in order to maximize the following:

$$
\max _{e} p \cdot q(e, \Omega)-c(e)
$$

For those workers whose output level places them under the minimum wage regime $(q<0)$, effort will be chosen to maximize the following:

$$
\max _{e} \bar{y}-\tau(q(e, \Omega)) k-c(e) .
$$

The first-order conditions for each are

$$
\begin{gathered}
p \cdot \frac{\partial q}{\partial e}-\frac{\partial c}{\partial e}=0 \\
-\frac{\partial \tau}{\partial q} \frac{\partial q}{\partial e} k-\frac{\partial c}{\partial e}=0
\end{gathered}
$$

Under the piece-rate regime, workers will supply effort such that the marginal cost of that effort is equal to additional compensation associated with that effort. For those workers being paid minimum wage, the incentive to supply effort is driven entirely by concerns about job security. ${ }^{15}$ Workers supply effort such that the marginal cost of that effort is equal to the increased probability of job retention associated with that effort times the value of job retention.

The threat of punishment for low levels of output is instrumental in inducing effort under the minimum wage regime. If workers are homogenous and firms set contracts optimally, the gains from job retention due to extra effort will be set equal to the piece-rate wage, i.e.,

$-\frac{\partial \tau}{\partial q} k=p$, such that effort exertion will be identical across both segments of the wage contract. If firms are unable to design optimal contracts, effort will differ across regimes. Of

\footnotetext{
${ }^{13}$ While minimum wage standards are typically fixed at an hourly rate, the fixed-length workday in our setting allows us to translate this into a daily rate.

${ }^{14}$ The assumption of perfect retention for those above the threshold is made for simplicity. As long as the probability of job retention is higher for those workers whose harvest levels exceed the threshold, the basic intuition behind the results that follow remain unchanged.

${ }^{15}$ This is conceptually quite similar to the model of efficiency wages and unemployment advanced in Shapiro and Stiglitz (1984), where high wages and the threat of unemployment induce workers to supply costly effort.
} 
particular concern is the situation in which termination incentives are low-powered; i.e.,

$-\frac{\partial \tau}{\partial q} k<p$. In this case, workers essentially have a limited liability contract, and thus have incentives to shirk under the minimum wage regime. Moreover, since the productivity impacts of pollution increase the probability of workers falling under the minimum wage portion of the compensation scheme, pollution will also indirectly increase the incentive to shirk, which we must account for in our econometric model.

\section{Econometric Model}

The worker maximization problem characterized in the previous section suggests the following econometric model:

$$
E[q \mid \Omega, \mathbf{X}]=P(q \geq 0 \mid \Omega, \mathbf{X}) \times E[q \mid \Omega, \mathbf{X}, q \geq 0]+(1-P(q \geq 0 \mid \Omega, \mathbf{X})) \times E[q \mid \Omega, \mathbf{X}, q<0],
$$

where $P$ is the probability a worker has output high enough to place them in the piece-rate regime, $1-P$ is the probability a worker's output places them in the minimum wage regime, and $\mathbf{X}$ are other factors that affect productivity (described in more detail below). We are primarily interested in the direct effect of pollution on productivity (the environmental productivity effect), and use two approaches for estimating this relationship. First, we estimate the following linear model:

$$
q=\beta^{o l s} \Omega+\theta^{o l s} \mathbf{X}+\varepsilon^{o l s}
$$

where $\beta^{\text {ols }}$ is the sum of the direct impact and, if it exists, the indirect impact of pollution on productivity via shirking. If the piece-rate contract is set optimally by imposing an appropriate termination threat as described in the previous section, there is no incentive to shirk, and $\beta^{\text {ols }}$ will only capture the environmental productivity effect. ${ }^{16}$ To the extent that contracts are not set optimally and there is an incentive to shirk in the minimum wage regime, $\beta^{o l s}$ will instead reflect not only the environmental productivity effect, but also the indirect effect due to the interaction of this pollution effect with shirking incentives, and hence provide an upper bound of the estimate of the environmental productivity effect.

To account for potential shirking, as a second approach we estimate equation (4) by artificially "bottom-coding" our data and estimating censored regression models. To do this, we leave all observations in the piece-rate regime as is, but assign a measure of productivity of 0 to all observations in the minimum wage regime. ${ }^{17}$ Thus, our estimation strategy can be viewed as a Type I Tobit model of the following form:

\footnotetext{
16 Although environmental conditions may affect workers, they may also have a direct impact on crops. While there is considerable evidence to support the claim that chronic exposure to ozone affects crop yield (see, e.g., Manning, Flagler, and Frenkel 2003), there is no evidence to support an effect from acute exposure.

${ }_{17}$ Because of our standardization of productivity, a value of 0 represents the value when workers switch from the minimum wage to piece rate regime.
} 


$$
\begin{gathered}
q^{*}=\beta^{c e n} \Omega+\theta^{c e n} \mathbf{X}+\varepsilon^{c e n} \\
q=q^{*} \text { if } q \geq 0 \\
q=0 \text { if } q<0,
\end{gathered}
$$

where $q^{*}$ is the latent measure of productivity. Because we are interested in the impact of pollution on actual productivity, which can take on values less than zero, the environmental productivity effect is the marginal effect of pollution on the latent variable $q^{*}$, which is simply $\beta^{c e n}$. Importantly, the actual values of productivity in the minimum wage regime will have no impact on the likelihood function, and hence on $\beta^{c e n}$. That is, if shirking occurs so that the distribution of productivity in the minimum wage regime is shifted to the left, this shift will no longer influence estimates of $\beta^{c e n}$ because they have been censored. Therefore, even if workers are shirking when paid minimum wage, our estimates of $\beta^{\text {cen }}$ will only capture the environmental productivity effect.

We include data from all crops in one regression by using the standardized measures of productivity described in the data section. We specify ozone in units of $10 \mathrm{ppb}$ since this value is close to prior and recently proposed policy changes for ozone in the United States. Given our standardization of the dependent variable, the coefficients can be interpreted as a standard deviation change in productivity from a $10 \mathrm{ppb}$ change in ozone. To control for other factors that may affect productivity, the vector $\mathbf{X}$ includes controls for gender, tenure with the farm (a quadratic), temperature, humidity, precipitation, wind speed, air pressure, solar radiation, and fine particulate matter (PM2.5), all measured as the mean over the typical workday. Since ozone is formed in part because of temperature and sunlight, it is essential that we properly control for these variables. To do this, we include a series of temperature indicator variables for every 2.5 degrees Fahrenheit, and also interact these indicators with solar radiation. To control for humidity, we use dew point temperature, a measure of absolute humidity that is not a function of temperature (Barreca 2012), and also include indicator variables for every 2.5 degrees Fahrenheit. We also include a series of dayof-week indicators to capture possible changes in productivity throughout the week, indicator variables for the crop to account for the mean shift in productivity from different contracts, and year-month dummies to control for trends in pollution and productivity within and across growing seasons. All standard errors are two-way clustered on the date because the same environmental conditions are assigned to all workers on a given day and on the worker to account for serial correlation in worker productivity (Cameron, Gelbach, and Miller 2011).

In addition to the aforementioned concerns regarding shirking, several additional primary threats to identification remain. As previously discussed, potential confounding due to weather may bias results, so we control flexibly for temperature and sunlight- - two important inputs into the ozone formation process. Furthermore, labor supply decisions may respond to ozone levels. Since we have measures of days and hours worked, we directly explore such responses. Lastly, if there is heterogeneity in the productivity effects of ozone and workers select into crops, this may hinder inference. To assess this, we explore both the heterogeneity of ozone effects and whether ozone or worker characteristics are related to crop assignment. 


\section{Results}

\section{A. Labor Supply Responses}

We begin by assessing our earlier claim that the labor supply of agricultural workers is insensitive to ozone levels in this setting. We estimate linear regression models for the decision to work and the number of hours worked (conditional on working), both with and without worker fixed effects. Shown in Table 2, the results in the first two columns, which focus on the decision to work, provide no evidence of a labor supply response to ozone. ${ }^{18}$ The second two columns also reveal that the number of hours worked is not significantly related to ozone levels. Even at the lower 95 percent confidence interval, a $10 \mathrm{ppb}$ increase in ozone is associated with a 0.28 drop in hours worked, which is a roughly 17 -minute decrease in hours worked. The insensitivity of these results to including worker fixed effects strengthens our confidence in these findings. Thus, consistent with our contention that avoidance behavior is not an issue in this setting, farm workers do not appear to adjust their work schedules in response to ozone levels.

\section{B. Main Productivity Results}

In Table 3, we present our main results. Column 1 presents results from our linear regression model. The estimated coefficient suggests that a $10 \mathrm{ppb}$ increase in ozone leads to a statistically significant decrease in productivity of 0.143 of a standard deviation. ${ }^{19}$ Based on the distribution of ozone and productivity in our sample, this estimate implies that a $10 \mathrm{ppb}$ decrease in ozone increases worker productivity by 5.5 percent. If wage contracts are set optimally, this is an unbiased estimate of the effect of ozone pollution. If contracts are not set optimally and workers shirk when the minimum wage binds, then this estimate will overstate the impact of ozone. In column 2 we show results from a Type I Tobit model, where we artificially censor observations when the minimum wage binds, and find a slightly larger estimate of 0.174 standard deviation effect from a $10 \mathrm{ppb}$ change in ozone, with the difference not statistically different from those found under the linear model. ${ }^{20}$

Since this Tobit model assumes normality and homoskedasticity, we assess the sensitivity of our results to these assumptions by estimating a censored median regression model, also displaying results from an uncensored median regression model as a reference point. ${ }^{21}$ Shown in column 3 , the median regression estimate of 0.164 is quite comparable to the linear regression estimate, which is not surprising given the distribution of productivity shown in Figure 1. The censored median regression estimate of 0.155, shown in column 4, is also quite similar to the estimates from the parametric censored models, lending support to the parametric assumptions of the Tobit model. The comparability of the four estimates in this table suggests that shirking due to the minimum wage is relatively minimal in this

\footnotetext{
18 Marginal effects from logit and probit models for the decision to work are virtually identical to the results from the linear probability model.

${ }^{19}$ Although we control for other local pollutants that might affect productivity, such as PM2.5, we do not control for $\mathrm{NO}_{\mathrm{X}}$ because it is a precursor to ozone formation. The transport of ozone, however, suggests that most of the $\mathrm{NO}_{\mathrm{X}}$ that contributes to the production of ozone is emitted in urban centers far from the farm. Consistent with this, if we add a control for local $\mathrm{NO}_{\mathrm{X}}$, the coefficient on ozone changes minimally.

${ }^{20}$ Consistent with these results, if we specify the dependent variable as the probability the worker reaches the piece-rate regime, we find that ozone reduces this probability by 5.9 percentage points and is statistically significant at the 10 percent level.

${ }^{21}$ We estimate a censored median model using the three-step procedure developed by Chernozhukov and Hong (2002).
} 
setting. Thus, the basic linear regression specification appears to yield unbiased estimates of the pollution productivity effect. ${ }^{22}$

In Table 4, we explore the sensitivity of the linear estimates to various additional assumptions. Column 1 repeats the baseline results. In column 2 we include worker fixed effects. Although this increases the explanatory power of our regressions considerably, the estimates for ozone fall somewhat to 0.101 , though this change is not statistically significant. Thus, consistent with the notion that workers are not selecting into employment on any given day based on ozone concentrations, cross-sectional and fixed effects estimates are quite similar.

Figure 1 provided some evidence that worker effort changes near the regime threshold, particularly for crop 1 where contracts are TPAP. If higher ozone levels reduce productivity and hence make it more likely for workers to fall into the minimum wage regime, this offsetting increase in effort may bias our results downward. In the next two columns of Table 4, we address this by excluding observations that are close to the regime threshold, varying our definition of "close." Consistent with expectations, our results are slightly larger as we exclude more observations, but these differences are minimal.

While our data agreement entitles us to productivity data aggregated to the daily level, we have time-stamped measures for crop 1, thus allowing us to explore how the impacts of ozone vary throughout the day. There are two notable limitations in this intraday analysis: (i) while pieces can be delivered at any time, environmental variables are measured by clock hour; and (ii) workers sometimes deliver several pieces at once. As a result, we construct hourly productivity measures using linear interpolation. We then use this linearly interpolated hourly data to examine intraday impacts by interacting ozone with the hour of the day, also controlling for hour of the day to account for changes in fatigue as the day progresses. Although the estimate for each hour is not statistically significant at conventional levels, which is not surprising given the measurement error induced by interpolation, the estimates suggest a pattern whereby ozone begins to impact productivity by 10 Ам and remains fairly steady from that point onward (results available upon request).

To address potential concerns about the cumulative effect of ozone exposure, we also present results that include one- and two-day lags of ozone. Since ozone levels may only reflect exposure on days when workers actually work, we limit our focus to days when workers have worked the previous day by excluding from our analysis the first one or two days of the workweek depending on how many lags we include in our specification. Shown in column 5 of Table 4 are results without any lags but excluding Monday, which are slightly higher than the baseline results. Including one lag of ozone, shown in column 6, we find that the coefficient on contemporaneous ozone remains the same, and lagged ozone is negative but statistically insignificant. The results in column 7 show that excluding the first two workdays continues to increase the contemporaneous coefficient on ozone. Including two lags of ozone, column 8 shows that the coefficient on contemporaneous ozone remains

${ }^{22}$ Consistent with the notion that shirking may be minimized through the threat of termination, we find that workers in the lower deciles of the productivity distribution are much more likely to separate from the farm than those in the upper deciles (unreported results available upon request from the authors). 
statistically significant and again unchanged, while one lag of ozone is statistically insignificant and the second lag is significant but positive, with colinearity of ozone across days as one possible explanation for the seemingly perverse sign. Most notably, the sum of the ozone coefficients is quite close to the contemporaneous effect regardless of the lags included. Together, these estimates suggest that the predominant effect of ozone is from same-day exposure, with an overnight respite from ozone sufficient for lung functioning to return to baseline levels. Moreover, this rapid recovery implies that the environmental productivity effects measured in this paper are predominantly impacting a healthy population. $^{23}$

Throughout our analysis, we have assumed ozone has a linear effect on productivity. In Figure 5, we present estimates that allow for a nonlinear effect by including indicator variables for every $4 \mathrm{ppb}$ of ozone, omitting < $30 \mathrm{ppb}$ as the reference category. As shown, the figure illustrates a relatively linear and steady increase in the productivity impacts of ozone over the entire range of ozone. Perhaps more importantly, the impacts appear to become statistically significant at $42-46 \mathrm{ppb}$, a concentration well below current air quality standards of $75 \mathrm{ppb}$ or even proposed reforms of $60 \mathrm{ppb}$.

\section{Heterogeneity of Productivity Results}

To assess whether individuals are differentially affected by ozone, we explore potential heterogeneity by interacting ozone with the limited worker characteristics in our dataset (tenure with the farm and gender) and with the crop, shown in Table $5 .{ }^{24}$ While workers with more experience may be more resilient to ozone by being better able to pace themselves throughout the day, column 2 finds no such evidence. Interacting ozone with a quadratic in tenure is statistically insignificant and the level effect of ozone is largely unchanged. Shown in column 3, we find that ozone has a smaller impact on productivity for women. ${ }^{25}$ While the magnitude of the difference between the effect for men and women is quite small, this result is contrary to laboratory studies that generally find no differential impact on lung functioning by gender (Hazucha, Folinsbee, and Bromberg 2003). Column 4 interacts ozone with crop dummy variables and reveals considerable heterogeneity in the productivity effects of ozone. The effect for crop 1 is significantly larger than crop 3 (the reference category), while the effect for crop 2 is significantly smaller. Since crops 2 and 3 are both paid time plus pieces, these differences are not driven by the different contract types.

To understand this source of heterogeneity, we first explore whether worker assignment to crop may explain these patterns. To assess this, we run a regression to predict working on crop 2 , limiting our sample to days when only crop 2 or 3 is harvested (since crop 1 is harvested in a different time period). As shown in column 5, gender is related to crop

\footnotetext{
${ }^{23}$ Recall from Section II that chamber studies suggest a rapid recovery from ozone exposure for healthy individuals. As further evidence consistent with these workers being generally healthy, we find that lagged ozone levels are not significantly related to the decision to work.

${ }^{24}$ We also estimated quantile regression models for each decile of worker productivity, and found that ozone has a similar effect on worker productivity throughout the entire productivity distribution (results available upon request).

25 Despite the smaller impact of ozone for females, the coefficient on gender reveals that female productivity is considerably lower than male productivity on average. As discussed in Table 1, gender is not reported for roughly 19 percent of the sample.
} 
assignment: females are more likely to select into crop 2. Given that females are less affected by ozone, this suggests that gender selection into crops may explain some of this heterogeneity. Based on estimates from columns 3-5, however, gender selection can only explain 7 percent of the crop heterogeneity, suggesting that other factors must explain the differential effects by crop. ${ }^{26}$ Importantly, ozone is not related to crop assignment, confirming that our estimates represent a valid estimate of the average treatment effect across the crops.

One explanation for this heterogeneity may be the differing physical demands placed on workers across crops. While crops 2 and 3 (grapes) are trellised such that harvestable fruit is waist to shoulder height, crop 1 (blueberries) grows closer to the ground, which requires considerable bending for workers and thus requires more energy to harvest. Within grapes, the crop 2 varietal is a delicate one that requires a slower and more careful harvest to avoid fruit damage, thus placing less physical demands on workers. Therefore, our findings that crop 1, which places the greatest physical demands on workers, is most affected by ozone and crop 2, which places the least physical demands, is least affected is consistent with laboratory studies (discussed in Section II) that find lung functioning impairment due to ozone is exacerbated by exercise.

\section{Conclusion}

In this paper, we merge a unique dataset on individual-level daily harvest rates for agricultural workers with data on environmental conditions to assess the impact of ozone pollution on worker productivity. We find that a $10 \mathrm{ppb}$ change in average ozone exposure results in a significant and robust 5.5 percent change in agricultural worker productivity. Importantly, this environmental productivity effect suggests that common characterizations of environmental protection as purely a tax on producers and consumers to be weighed against the consumption benefits associated with improved environmental quality may be misguided. Environmental protection can also be viewed as an investment in human capital, and its contribution to firm productivity and economic growth should be incorporated in the calculus of policymakers.

Our results also speak to the ongoing debates on ozone policy. Ozone pollution continues to be a pervasive environmental issue throughout much of the world. Debates over the optimal level of ozone have ensued for many years, and current efforts to strengthen these standards remain contentious. Defining regulatory standards depends, in part, on the benefits associated with avoided exposure, which has traditionally been estimated through a focus on high-visibility health effects such as hospitalizations. The labor productivity impacts measured in this paper help make these benefits calculations more complete. Our results indicate that ozone, even at levels below current air-quality standards in most of the world, has significant negative impacts on worker productivity, suggesting that the strengthening of regulations on ozone pollution would yield additional benefits.

${ }^{26}$ We obtain this estimate of 7 percent by multiplying the differential effect of ozone by gender ( 0.04$)$ by the selection into crop 2 (0.257), and dividing it by the amount of heterogeneity (0.149). 
These impacts of ozone on agricultural workers are also important in their own right. A back-of-the envelope calculation that applies the environmental productivity effect estimated in the Central Valley of California to the whole of the United States suggests that the $10 \mathrm{ppb}$ reduction in the ozone standard currently being considered by EPA would translate into an annual cost savings of approximately $\$ 700$ million in labor expenditure. ${ }^{27}$ In the developing world, where national incomes depend more heavily on agriculture, these productivity effects are likely to have a much larger impact on the economy and the well-being of households. Nearly 1.1 billion individuals -35 percent of the active labor force-work in the agricultural sector worldwide (International Labour Organization 2011). The impacts of ozone may be especially large in countries like India, China, and Mexico, where rapid industrial growth and automobile penetration contribute precursor chemicals that contribute to substantially higher levels of ozone pollution.

While the impacts of ozone on agricultural productivity are large, the generalizability of these findings to other pollutants and industries is unclear. Agricultural workers face considerably higher levels of exposure to pollution than individuals who work indoors. That said, roughly 11.8 percent of the US labor force works in an industry with regular exposure to outdoor conditions, and this figure is much higher for middle- and lower-income countries (Graff Zivin and Neidell forthcoming). Moreover, many forms of outdoor pollution diminish indoor air quality as well. For example, indoor penetration of fine particulate matter ranges from 38-94 percent for typical residential homes in the United States (Abt et al. 2000). Examining the generalizability of the environmental productivity effect estimated in this paper to other pollutants and industries represents a fruitful area for future research.

\section{Acknowledgments}

We thank numerous individuals and seminar participants at RAND, UC-Irvine, Maryland, Cornell, Tufts, Michigan, University of Washington, University of British Columbia, CUNY Graduate Center, Yale University, Columbia, UC-San Diego, and the NBER Health Economics meeting for helpful suggestions. We are also particularly indebted to Udi Sosnik for helping to make this project possible, and Shlomo Pleban for assistance in collecting the data, both of Orange Enterprises. We are grateful for funding from the National Institute of Environmental Health Sciences (1R21ES019670-01), the Property and Environment Research Center, and seed grants from the Institute for Social and Economic Research and Policy and the Northern Manhattan NIEHS.

\section{References}

Abt, Eileen; Suh, Helen H.; Catalano, Paul; Koutrakis, Petros. Relative Contribution of Outdoor and Indoor Particle Sources to Indoor Concentrations. Environmental Science and Technology. 2000; 34(17):3579-87.

Auffhammer, Maximilian; Kellogg, Ryan. Clearing the Air? The Effects of Gasoline Content Regulation on Air Quality. American Economic Review. 2011; 101(6):2687-722.

Bandiera, Oriana; Barankay, Iwan; Rasul, Imran. Social Preferences and the Response to Incentives: Evidence from Personnel Data. Quarterly Journal of Economics. 2005; 120(3):917-62.

\footnotetext{
${ }^{27}$ Total labor expenditure in US agriculture was approximately \$26.5 billion in 2007 (United States Department of Agriculture 2009) Ozone season in California runs from April through October. Using the conservative assumption that the seasonal distribution of agricultural labor expenditure is flat (it is likely lower in winter) yields a total annual expenditure of $\$ 13.25$ billion that is exposed to ozone productivity risk. The calculation assumes that the new standard shifts the entire distribution of ozone down by $10 \mathrm{ppb}$ and not just values that exceed air quality standards.
} 
Bandiera, Oriana; Barankay, Iwan; Rasul, Imran. Social Incentives in the Workplace. Review of Economic Studies. 2010; 77(2):417-58.

Banzhaf, H Spencer; Walsh, Randall P. Do People Vote with Their Feet? An Empirical Test of Tiebout's Mechanism. American Economic Review. 2008; 98(3):843-63.

Barreca, Alan I. Climate Change, Humidity, and Mortality in the United States. Journal of the American Medical Association. 2012; 292(19):2372-78.

Blanchard, Charles; Tanenbaum, Shelley. Differences between Weekday and Weekend Air Pollutant Levels in Southern California. Journal of the Air and Waste Management Association. 2003; 53(7): 816-28. [PubMed: 12880070]

Brauer, Michael; Brook, Jeffrey. Personal and Fixed-Site Ozone Measurements with a Passive Sampler. Journal of the Air and Waste Management Association. 1995; 45(7):529-37. [PubMed: 7634124]

Brauer, Michael; Blair, Jim; Vedal, Sverre. Effect of Ambient Ozone Exposure on Lung Function in Farm Workers. American Journal of Respiratory and Critical Care Medicine. 1996; 154(4):981-87. [PubMed: 8887595]

California Air Resources Board. California Environmental Protection Agency; 2012. Air Quality and Meteorological Information System. www.arb.ca.gov/aqmis2/aqmis2.php [accessed September 26, 2012]

Cameron, A Colin; Gelbach, Jonah; Miller, Douglas. Robust Inference with Multiway Clustering. Journal of Business and Economic Statistics. 2011; 29(2):238-49.

Carson, Richard T.; Koundouri, Phoebe; Nauges, Celine. Arsenic Mitigation in Bangladesh: A Household Labor Market Approach. American Journal of Agricultural Economics. 2011; 93(2): 407-14.

Chan, Chang-Chuan; Wu, Tsung-Huan. Effects of Ambient Ozone Exposure on Mail Carriers' Peak Expiratory Flow Rates. Environmental Health Perspectives. 2005; 113(6):735-38. [PubMed: 15929897]

Chay, Kenneth Y.; Greenstone, Michael. The Impact of Air Pollution on Infant Mortality: Evidence from Geographic Variation in Pollution Shocks Induced by a Recession. Quarterly Journal of Economics. 2003; 118(3):1121-67.

Chay, Kenneth Y.; Greenstone, Michael. Does Air Quality Matter? Evidence from the Housing Market. Journal of Political Economy. 2005; 113(2):376-424.

Chernozhukov, Victor; Hong, Han. Three-Step Sensored Quantile Regression and Extramarital Affairs. Journal of the American Statistical Association. 2002; 97(459):872-82.

Crocker, Thomas D.; Horst, Robert L, Jr. Hours of Work, Labor Productivity, and Environmental Conditions: A Case Study. Review of Economics and Statistics. 1961; 63(3):361-68.

Currie, Janet; Neidell, Matthew. Air Pollution and Infant Health: What Can We Learn from California's Recent Experience? Quarterly Journal of Economics. 2005; 120(3):1003-30.

Dockery, Douglas; Pope, C Arden; Xu, Xiping; Spengler, John D.; Ware, James H.; Fay, Martha E.; Ferris, Benjamin G., Jr; Speizer, Frank E. An Association between Air Pollution and Mortality in Six U.S. Cities. The New England Journal of Medicine. 1993; 329(24):1753-59. [PubMed: 8179653]

Environmental Protection Agency. Air Quality Criteria Document for Ozone. Washington, DC: Environmental Protection Agency; 2006.

Environmental Protection Agency. National Ambient Air Quality Standards for Ozone (Proposed Rule). Federal Register. 2010; 75(11):2938-3052.

Folinsbee, Lawrence; Hazucha, Milan. Time Course of Response to Ozone Exposure in Healthy Adult Females. Inhalation Toxicology. 2000; 12(3):151-67. [PubMed: 10715622]

Folinsbee, Lawrence; Horvath, Steven. Persistence of the Acute Effects of Ozone Exposure. Aviation, Space, and Environmental Medicine. 1986; 57(12):1136-43.

Gong, Henry, Jr; Bradley, Patrick; Simmons, Michael; Tashkin, Donald. Impaired Exercise Performance and Pulmonary Function in Elite Cyclists during Low-Level Ozone Exposure in a Hot Environment. American Review of Respiratory Disease. 1986; 134(3):726-33. [PubMed: 3767129] 
González-Alonso, José; Teller, Christina; Andersen, Signe; Jensen, Frank; Hyldig, Tino; Nielsen, Bodil. Influence of Body Temperature on the Development of Fatigue during Prolonged Exercise in the Heat. Journal of Applied Physiology. 1999; 86(3):1032-39. [PubMed: 10066720]

Graff Zivin, Joshua; Neidell, Matthew. Temperature and the Allocation of Time: Implications for Climate Change. Journal of Labor Economics. Forthcoming.

Graff Zivin, Joshua; Neidell, Matthew. The Impact of Pollution on Worker Productivity: Dataset. American Economic Review. 2012. http://dx.doi.org/10.1257/aer.102.7.3652

Hancock, Peter; Warm, Joel. A Dynamic Model of Stress and Sustained Attention. Human Factors. 1989; 31(5):519-37. [PubMed: 2625347]

Hancock, Peter; Ross, Jennifer; Szalma, James. A Meta-analysis of Performance Response under Thermal Stressors. Human Factors. 2007; 49(5):851-77. [PubMed: 17915603]

Hanna, Rema; Oliva, Paulina. National Bureau of Economic Research Working Paper 17302. 2011. The Effect of Pollution on Labor Supply: Evidence from a Natural Experiment in Mexico City.

Hazucha, Milan; Folinsbee, Lawrence; Bromberg, Philip. Distribution and Reproducibility of Spirometric Response to Ozone by Gender and Age. Journal of Applied Physiology. 2003; 95(5): 1917-25. [PubMed: 12871968]

Hausman, Jerry A.; Ostro, Bart D.; Wise, David A. National Bureau of Economic Research Working Paper 1263. 1984. Air Pollution and Lost Work.

International Labour Organization. Global Employment Trends 2011: The Challenge of a Jobs Recovery. Geneva, Switzerland: International Labour Organization; 2011.

Kulle, Thomas; Sauder, Larry; Hebel, J Richard; Chatham, Marie. Ozone Response Relationships in Healthy Nonsmokers. American Review of Respiratory Disease. 1985; 132(1):36-41. [PubMed: 4014870]

Lazear, Edward P. Performance Pay and Productivity. American Economic Review. 2000; 90(5): 1346-61.

Manning, William; Flagler, Richard; Frenkel, MA. Assessing Plant Responses to Ambient Ozone: Growth of Ozone-Sensitive Loblolly Pine Seedlings Treated with Ethylenediurea (EDU) and Sodium Erythorbate (NaE). Environmental Pollution. 2003; 126(1):73-81. [PubMed: 12860104]

McDonnell, William; Horstman, Donald; Hazucha, Milan; Seal, Elston, Jr; Haak, Edward; Salaam, Sa'id; House, Denis. Pulmonary Effects of Ozone Exposure during Exercise: Dose-Response Characteristics. Journal of Applied Physiology. 1983; 54(5):1345-52. [PubMed: 6863094]

Neidell, Matthew. Information, Avoidance Behavior, and Health: The Effect of Ozone on Asthma Hospitalizations. Journal of Human Resources. 2009; 44(2):450-78.

O'Neill, Marie; Ramirez-Aguilar, Matiana; Meneses-Gonzalez, Fernando; Hernández-Avila, Mauricio; Geyh, Alison; Sienra-Monge, Juan Jose; Romieu, Isabelle. Ozone Exposure among Mexico City Outdoor Workers. Journal of the Air and Waste Management Association. 2003; 53(3):339-46. [PubMed: 12661692]

Ostro, Bart D. The Effects of Air Pollution on Work Loss and Morbidity. Journal of Environmental Economics and Management. 1983; 10(4):371-82.

Paarsch, Harry J.; Shearer, Bruce. The Response of Worker Effort to Piece Rates: Evidence from the British Columbia Tree-Planting Industry. Journal of Human Resources. 1999; 34(4):643-67.

Paarsch, Harry J.; Shearer, Bruce. Piece Rates, Fixed Wages, and Incentive Effects: Statistical Evidence from Payroll Records. international Economic Review. 2000; 41(1):59-92.

Pope, C Arden, III; Burnett, Richard; Thun, Michael; Calle, Eugenia; Krewski, Daniel; Ito, Kazuhiko; Thurston, George. Lung Cancer, Cardiopulmonary Mortality and Long-Term Exposure to Fine Particulate Air Pollution. Journal of the American Medical Association. 2002; 287(9):1132-41. [PubMed: 11879110]

Shapiro, Carl; Stiglitz, Joseph. Equilibrium Unemployment as a Worker Discipline Device. American Economic Review. 1984; 74(3):433-44.

Shi, Lan. Incentive Effect of Piece-Rate Contracts: Evidence from Two Small Field Experiments. B E Journal of Economic Analysis and Policy: Topics in Economic Analysis and Policy. 2010; 10(1)

Sillman, Sanford. The Relation between Ozone, NOx, and Hydrocarbons in Urban and Polluted Rural Environments. Atmospheric Environment. 1999; 33(12):1821-45. 
Tepper, Jeffrey; Costa, Daniel; Lehmann, James; Weber, Mary; Hatch, Gary. Unattenuated Structural and Biochemical Alterations in the Rat Lung during Functional Adaptation to Ozone. American Review of Respiratory disease. 1989; 140(2):493-501. [PubMed: 2527482]

United States Department of Agriculture. 2007 Census of Agriculture. Washington, DC: USDA, National Agricultural Statistics Service; 2009.

White House. Executive Order \#12866: Regulatory Planning and Review. 58 FR 51735. Oct 4.1993 1994. 


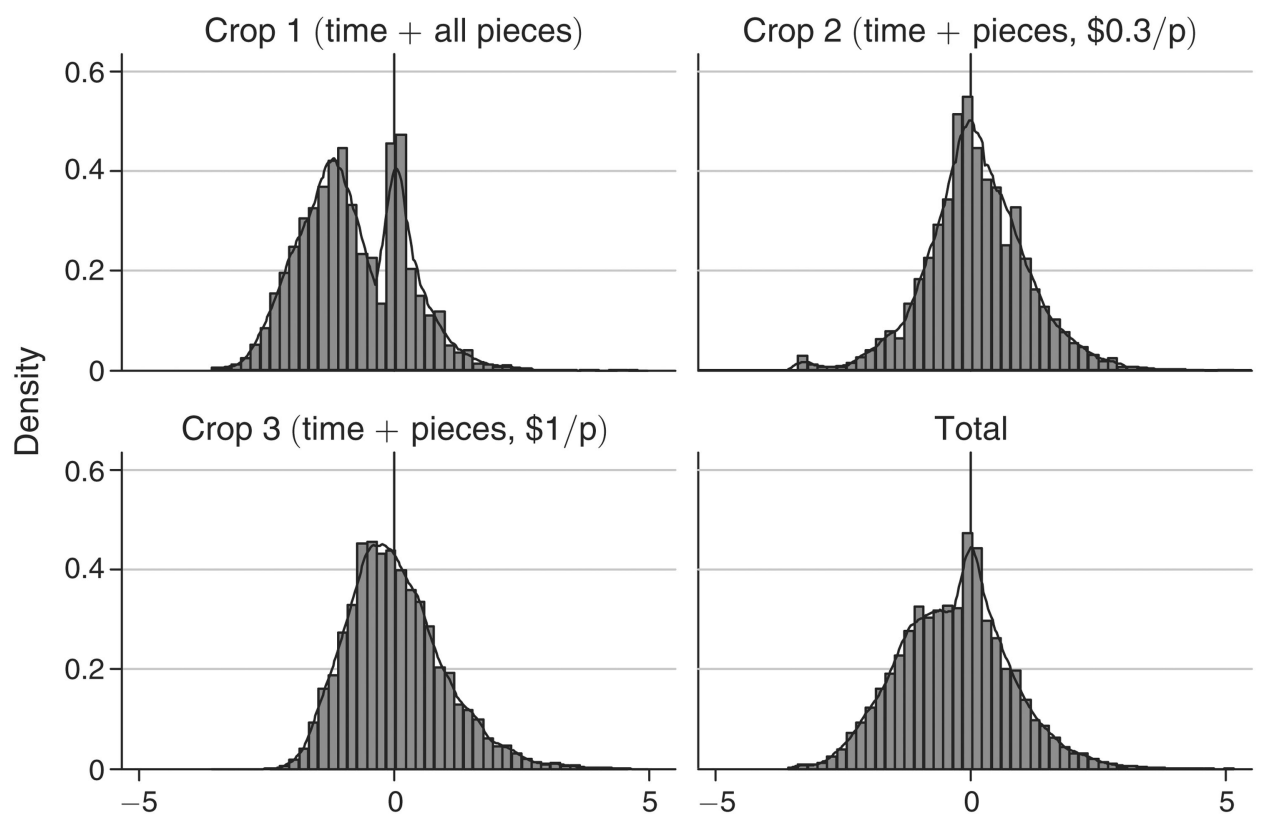

Figure 1. Standardized Average Hourly Pieces Collected by Crop and for All Crops

Notes: This figure plots the standardized average hourly pieces for each of the three crops and all crops, along with a nonparametric kernel density estimate. We standardize average hourly productivity by subtracting the minimum number of pieces per hour required to reach the piece-rate regime and dividing by the standard deviation of productivity for each crop. The vertical line reflects the regime threshold for crossing from the minimum wage to the piece-rate regime, which is zero for all crops given the standardization. 


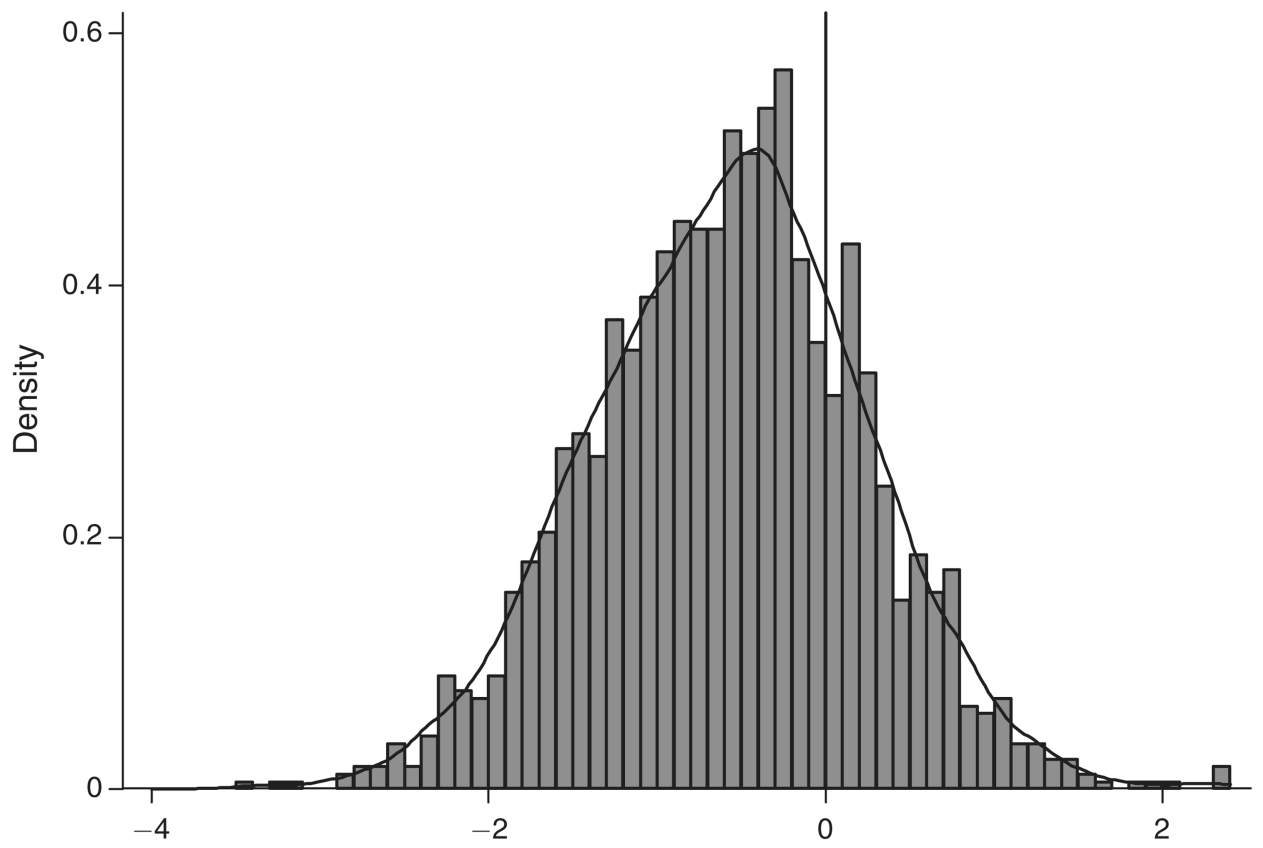

Figure 2. Variation in Productivity by Worker, All Crops

Notes: This figure plots the mean of the standardized average hourly pieces for all crops by worker. We standardize average hourly productivity by subtracting the minimum number of pieces per hour required to reach the piece-rate regime and dividing by the standard deviation of productivity for each crop. 


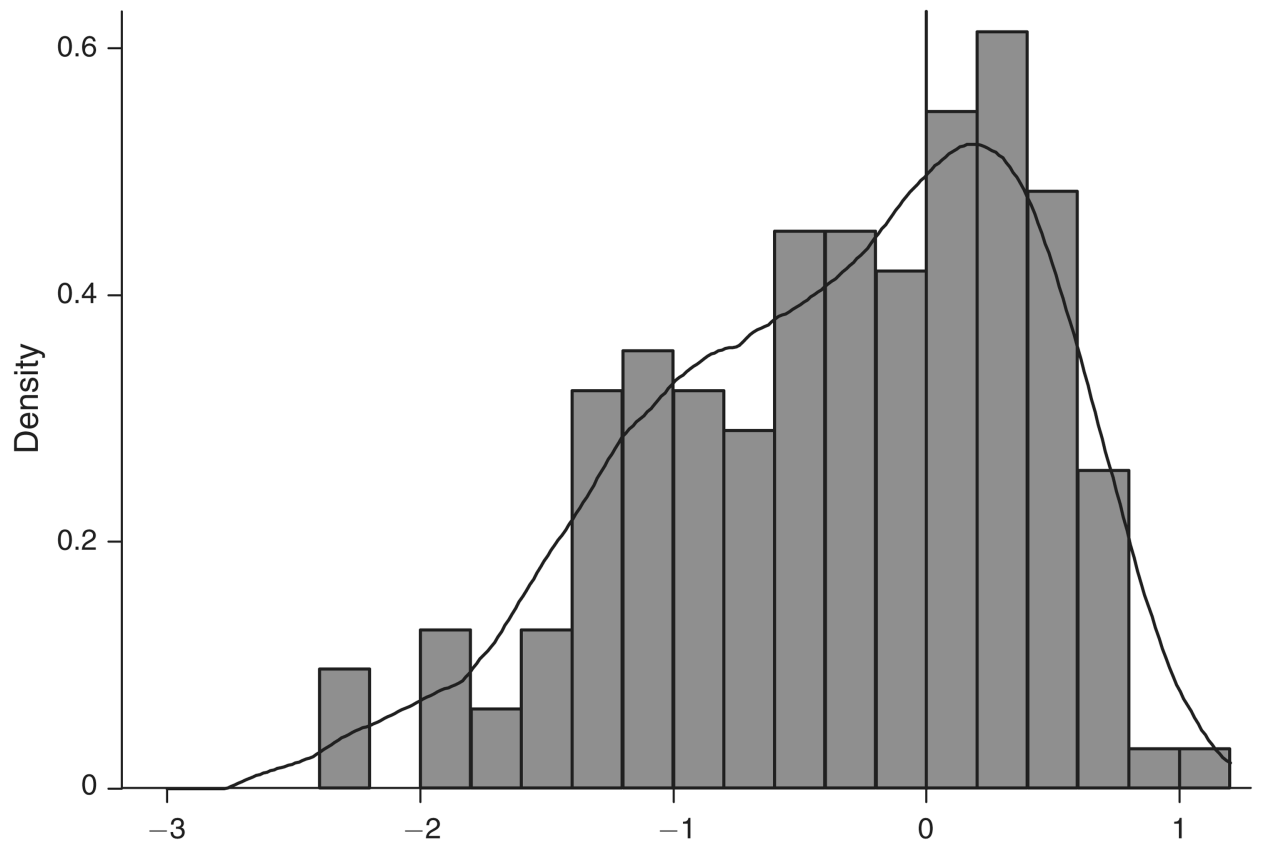

Figure 3. Variation in Productivity by Day, All Crops

Notes: This figure plots the mean of the standardized average hourly pieces for all crops by day. We standardize average hourly productivity by subtracting the minimum number of pieces per hour required to reach the piece rate regime and dividing by the standard deviation of productivity for each crop. 
Panel A. Year 2009

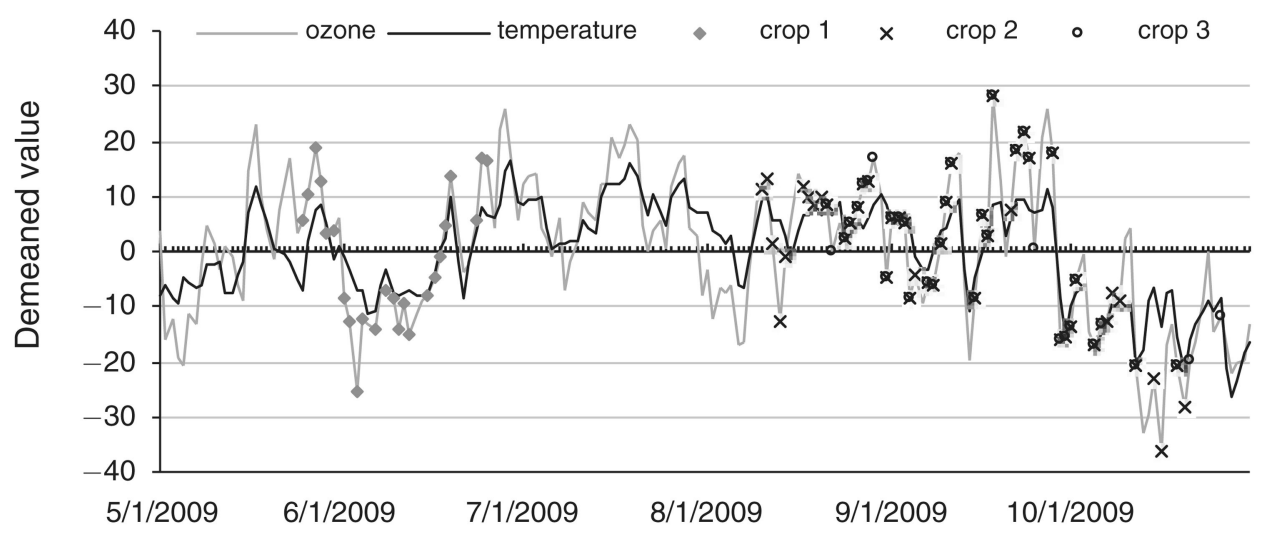

Panel B. Year 2010

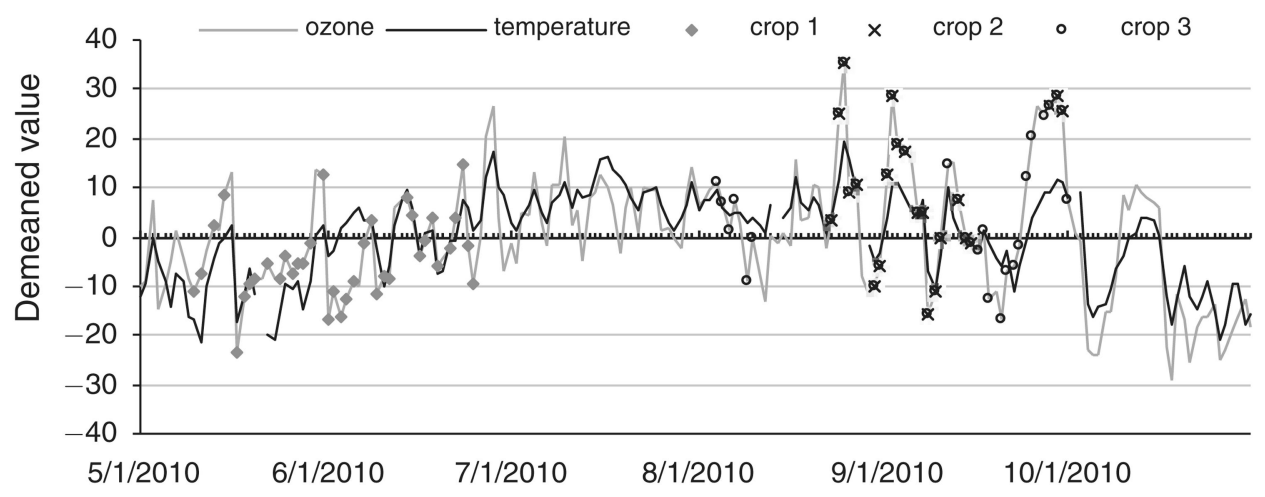

Figure 4. Average Demeaned Daily Ozone and Temperature, and Crop Harvest Days, by Year Note: These figures plot demeaned ozone and temperature levels by day for 2009 and 2010, and indicate the days each of the three crops were harvested. 


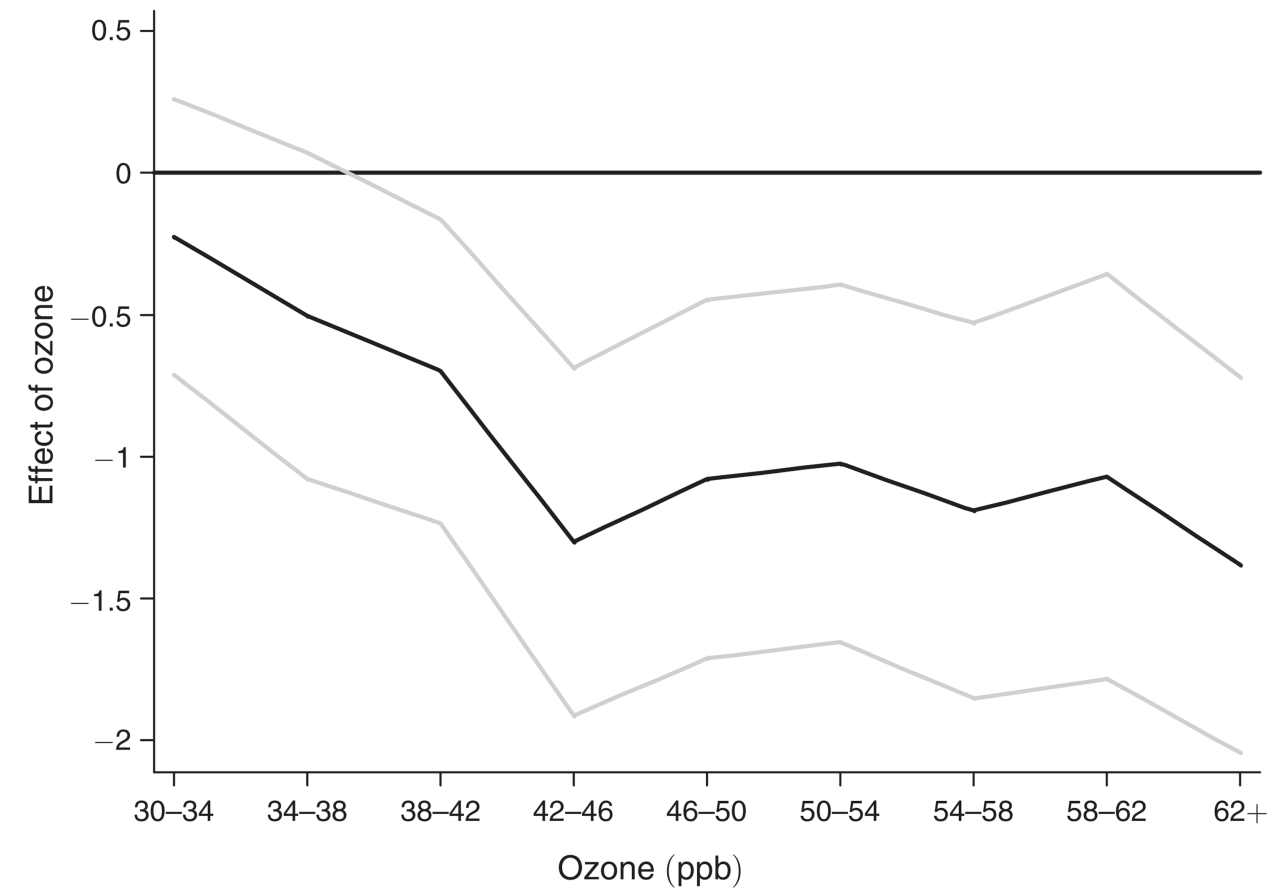

Figure 5. Regression Results of the Effect of Ozone on Productivity Using More Flexible Controls for Ozone

Notes: This figure plots the coefficients for the ozone indicator variables $(<30 \mathrm{ppb}$ reference category), with the 95 percent confidence interval based on standard errors clustered on date and worker in gray. The dependent variable is standardized hourly pieces collected, which is the average hourly productivity minus the minimum number of pieces per hour required to reach the piece rate regime, divided by the standard deviation of productivity for each crop. The regression includes controls for gender, farm tenure (quadratic), temperature ( 2.5 degree $\mathrm{F}$ indicators), solar radiation, temperature $(2.5$ degree $\mathrm{F}$ indicators $) \times$ solar radiation, air pressure, wind speed, dew point (2.5 degree $\mathrm{F}$ indicators), precipitation, particulate matter < $2.5 \mu_{g}$, day of week dummies, month $\times$ year dummies, and piece rate contract type dummies. All environmental variables are the mean of hourly values from 6 Ам -3 рм. 


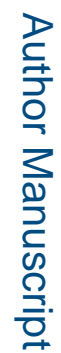

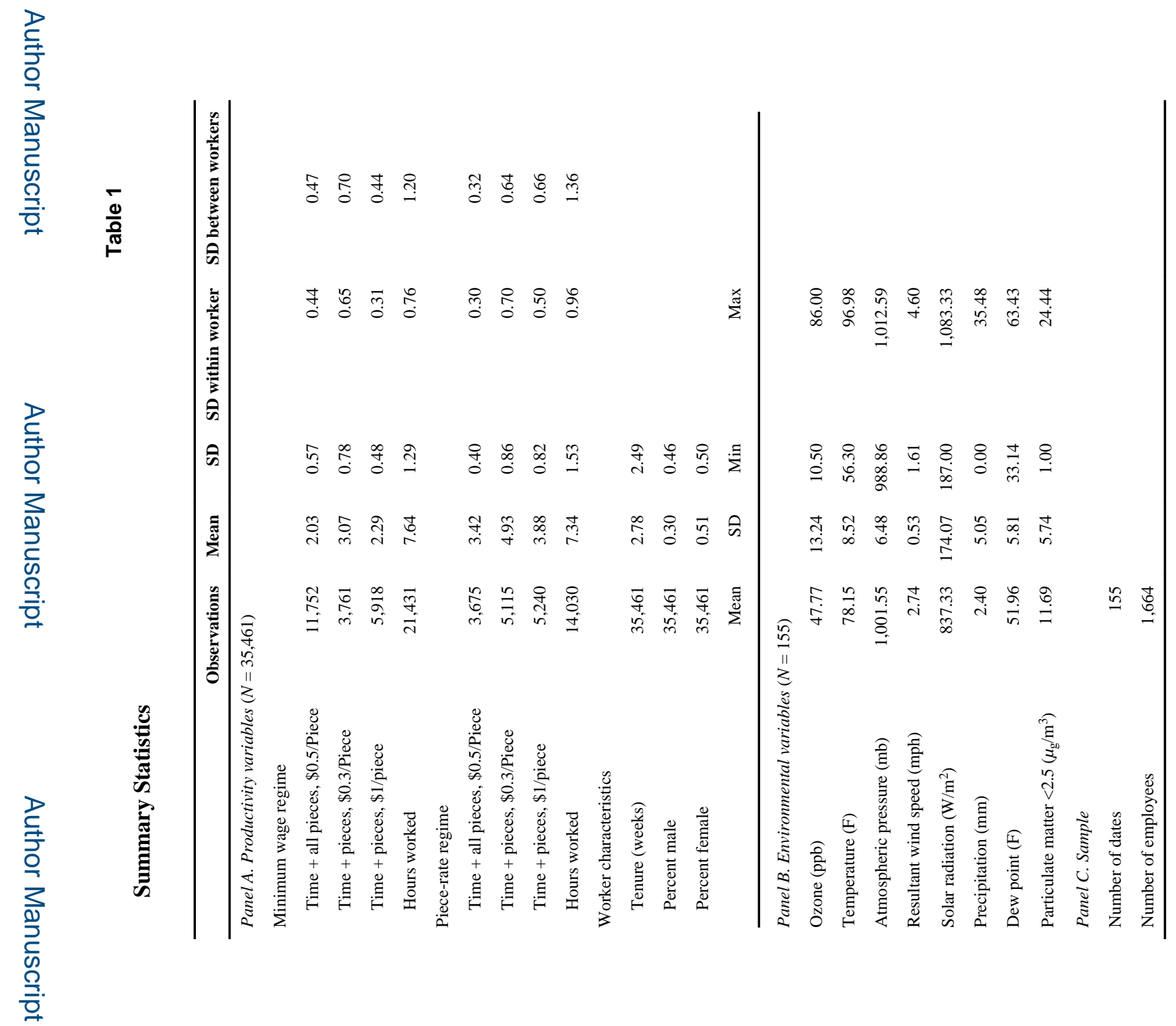

Am Econ Rev. Author manuscript; available in PMC 2015 September 21. 


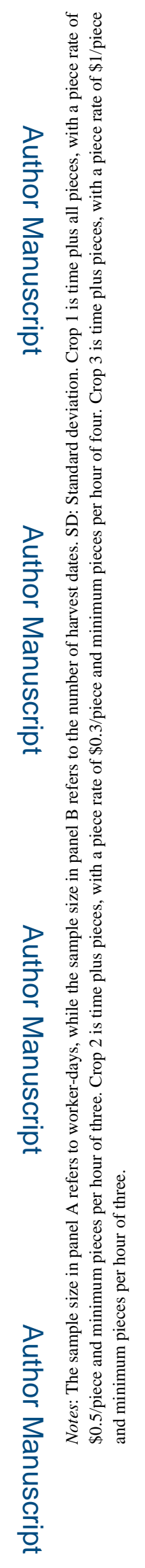


Table 2

\section{Regression Results of the Effect of Ozone on Avoidance Behavior}

\begin{tabular}{|c|c|c|c|c|}
\hline & \multicolumn{2}{|c|}{ Extensive margin: probability(work) } & \multicolumn{2}{|c|}{ Intensive margin: hours worked } \\
\hline & (1) & (2) & (3) & (4) \\
\hline Ozone (10 ppb) & $0.001[0.026]$ & $-0.001[0.027]$ & $0.015[0.149]$ & $0.026[0.154]$ \\
\hline Worker fixed effect & $\mathrm{N}$ & $\mathrm{Y}$ & $\mathrm{N}$ & $\mathrm{Y}$ \\
\hline Mean of dep. var. & 0.905 & 0.905 & 7.52 & 7.52 \\
\hline Observations & 39,223 & 39,223 & 35,461 & 35,461 \\
\hline$R^{2}$ & 0.12 & 0.17 & 0.33 & 0.36 \\
\hline
\end{tabular}

Notes: Standard errors clustered on date and worker in brackets. Hours worked is conditional upon working. All regressions include controls for gender, farm tenure (quadratic), temperature ( 2.5 degree $\mathrm{F}$ indicators), solar radiation, temperature $(2.5$ degree $\mathrm{F}$ indicators $) \times$ solar radiation, air pressure, wind speed, dew point ( 2.5 degree $\mathrm{F}$ indicators), precipitation, particulate matter $<2.5 \mu \mathrm{g}$, day of week dummies, month $\times$ year dummies, and piece rate contract type dummies. All environmental variables are the mean of hourly values from 6 AM-3 PM. 
Table 3

Main Regression Results of the Effect of Ozone on Productivity

\begin{tabular}{lcccc}
\hline & $(\mathbf{1})$ & $\mathbf{( 2 )}$ & $\mathbf{( 3 )}$ & $\mathbf{( 4 )}$ \\
\hline Ozone $(10 \mathrm{ppb})$ & $-0.143^{* *}[0.068]$ & $-0.174^{* *}[0.074]$ & $-0.164[0.109]$ & $-0.155[0.100]$ \\
Model & Linear & Tobit & Median & Censored median \\
Mean of dep. var. & -0.323 & -0.323 & -0.323 & -0.323 \\
Observations & 35,461 & 35,461 & 35,461 & 25,955 \\
(Psuedo) $R^{2}$ & 0.34 & 0.12 & 0.22 & 0.28 \\
\hline
\end{tabular}

Notes: Standard errors clustered on date and worker in brackets. The dependent variable is standardized hourly pieces collected, which is the average hourly productivity minus the minimum number of pieces per hour required to reach the piece rate regime, divided by the standard deviation of productivity for each crop. All regressions include controls for gender, farm tenure (quadratic), temperature (2.5 degree F indicators), solar radiation, temperature ( 2.5 degree $\mathrm{F}$ indicators $) \times$ solar radiation, air pressure, wind speed, dew point ( 2.5 degree $\mathrm{F}$ indicators), precipitation, particulate matter $<2.5 \mu_{\mathrm{g}}$, day of week dummies, month $\times$ year dummies, and piece rate contract type dummies. All environmental variables are the mean of hourly values from 6 AM- 3 PM. Bootstrapped standard errors for both median regressions were obtained using 250 replications.

$* * *$

Significant at the 1 percent level.

**

Significant at the 5 percent level.

* Significant at the 10 percent level. 


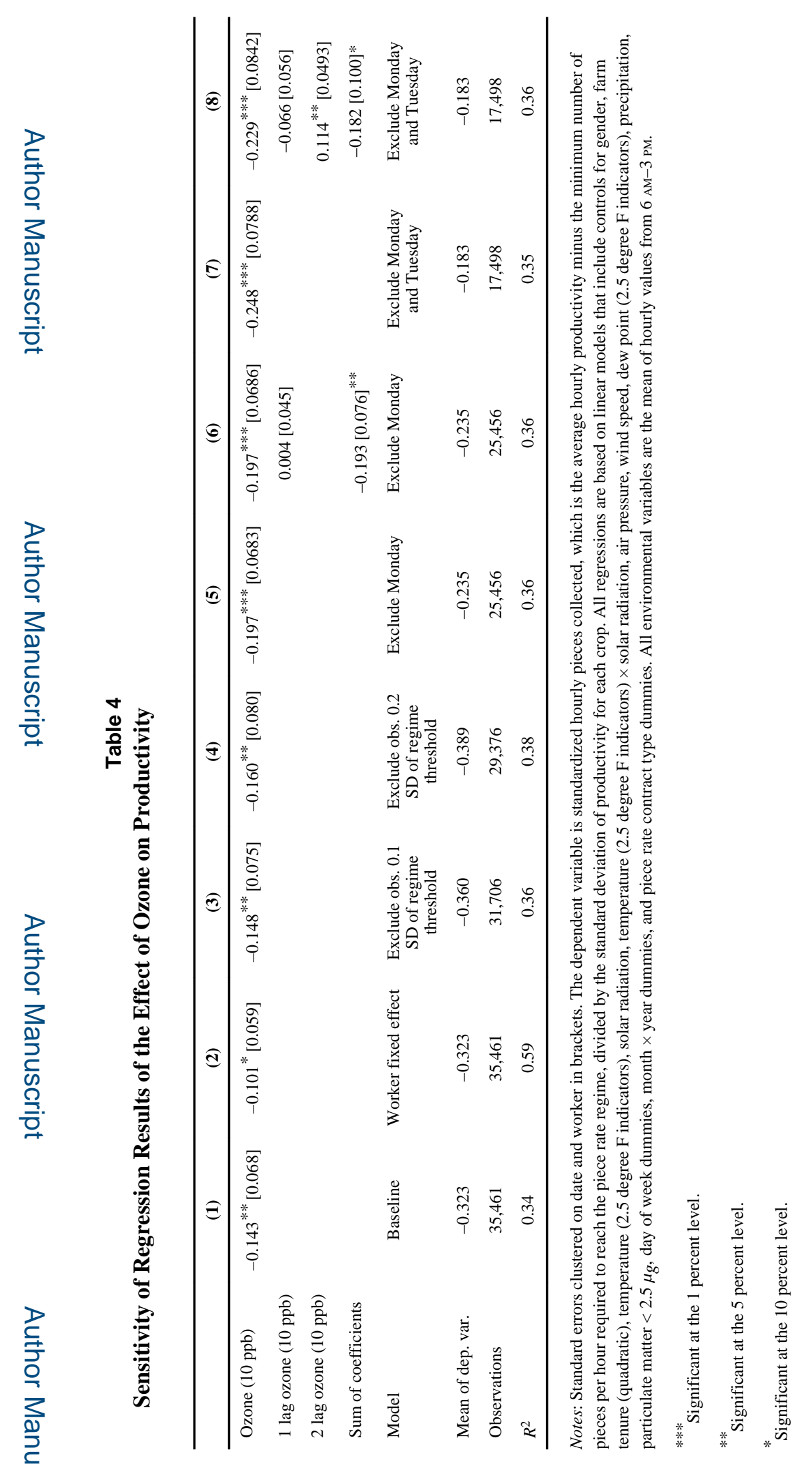

Am Econ Rev. Author manuscript; available in PMC 2015 September 21. 


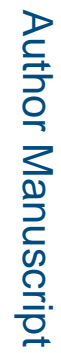
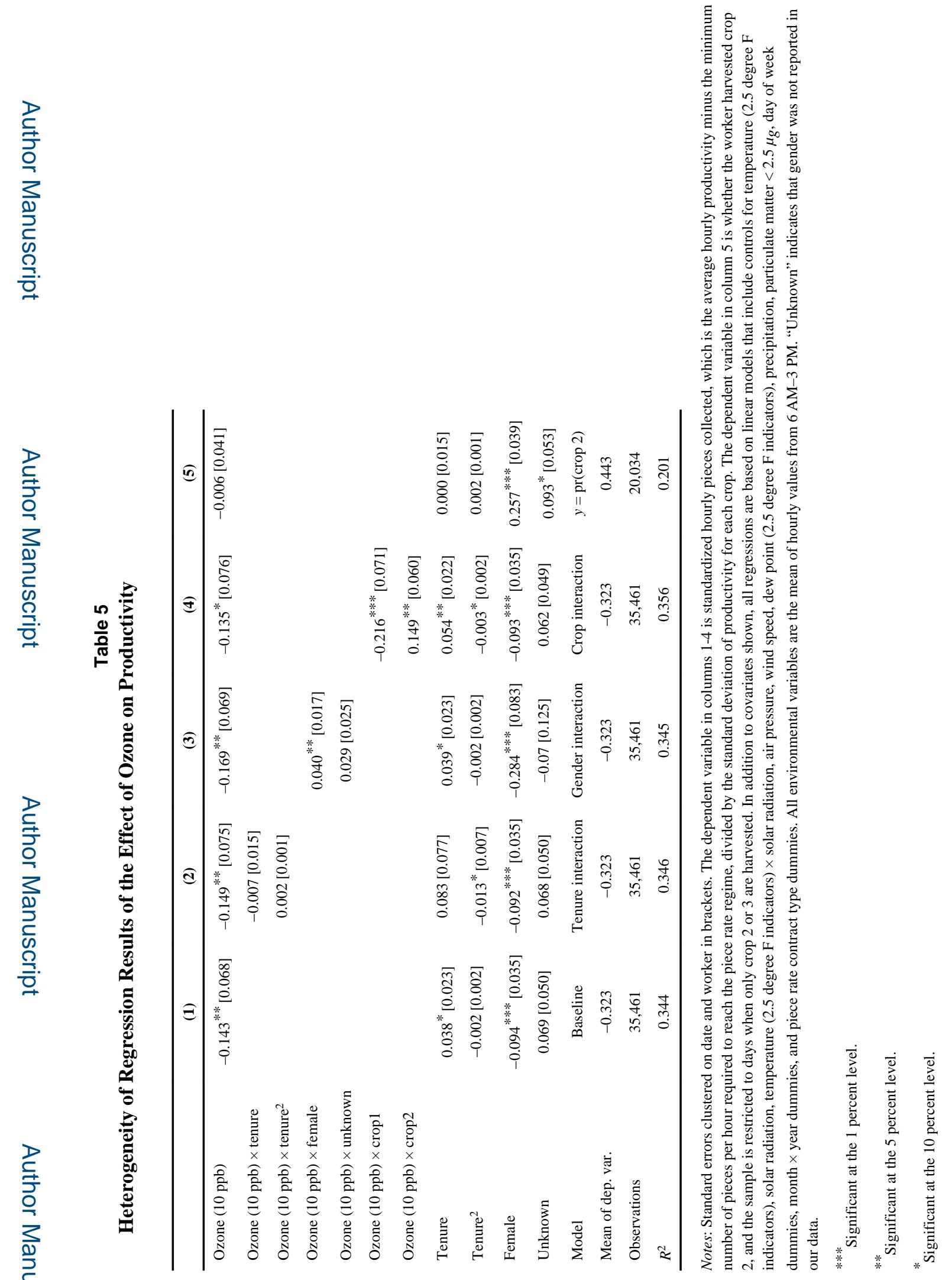

Am Econ Rev. Author manuscript; available in PMC 2015 September 21. 